\title{
A NOVEL METHOD FOR MATERIAL SELECTION IN INDUSTRIAL APPLICATIONS
}

\author{
L. Anojkumar ${ }^{1}$, M. Ilangkumaran ${ }^{2}$, B.Kirubakaran ${ }^{3}$, L.Arulmurugan ${ }^{4}$, S. Mohamed Hassan $^{5}$, \\ S.Lokesh $^{6}$
}

${ }^{1}$ Assistant professor, Department of Mechatronics Engineering, K.S.Rangasamy College of Technology, Tamilnadu, India

${ }^{2}$ professor, Department of Mechatronics Engineering, K.S.Rangasamy College of Technology, Tamilnadu, India

${ }^{3}$ Assistant professor, Department of Mechatronics Engineering, K.S.Rangasamy College of Technology, Tamilnadu, India

${ }^{4}$ Assistant professor, Department of Mechatronics Engineering, K.S.Rangasamy College of Technology, Tamilnadu, India

${ }^{5}$ Student, Department of Mechatronics Engineering, K.S.Rangasamy College of Technology, Tamilnadu, India

${ }^{6}$ Student, Department of Mechatronics Engineering, K.S.Rangasamy College of Technology, Tamilnadu, India

\begin{abstract}
Selection of material for a particular task in an industrial process is beneficiary for performance enhancement and profit margin. Inappropriate chosen material may reduce the maximum efficiency of the machines. As a wide range of material selection methods are available that consider various conflicting factors such as mechanical, environmental and chemical factors. In this study, a combination of non-linear normalization with weighting factor approach method is illustrated and explained. This method helps in selecting the material under quantitative analysis and capable of selecting the appropriate material using digital logical method. To overcome the consequence in the digital logic method a non-linear normalization is combined with DL method is employed to obtain better result. The results of these two methods are compared to explore the flexibility in the MDL method. The proposed model is to support significantly for selecting suitable material in industry applications. The result of the proposed model obtains M5 is the best suitable material.
\end{abstract}

Keywords: Attributes, DL method, MDL method, Material selection, weighting factor, Scaled property value.

\section{INTRODUCTION}

Selecting the most appropriate materials for diverse engineering application is one of the most prominent activities in the design process, in order to maintain their competitive edge and to increase profit margin [5]. An inappropriate selection of material may result in damage or failure of an assembly and significantly decreases the performance [1], [6]. The large number of available materials, together with the complex relationships between the various selection constraints, often make the selection process a difficult task [5]. When selecting materials, a large number of factors should be taken into account. These factors for material include mechanical properties (Young's Modulus, strength, yield stress, elasticity, fatigue, creep resistance, ductility, hardness and toughness), physical properties (crystal structure, density, melting point, vapour pressure, viscosity, porosity, permeability, reflectivity, transparency, optical properties, dimensional stability), magnetic properties, electrical (resistivity, permittivity, dielectric strength), thermal and radiation (specific heat, conductivity, expansively, diffusivity, reflectivity, emissivity), surface (texture, corrosively, wear resist), manufacturing properties (machinability, formability, weld ability, cast ability, heat treatability, etc.), material cost, reliability, durability, recycle ability, material impact on environment, performance characteristics, availability, fashion, market trends etc. However in mechanical design, mechanical properties are of prime concern [3].

For materials considering mechanical properties, Ashby introduced material selection charts for a wide range of materials [3]. This chart helps in selecting the material based on approximation and not on precise values. This approach allows to identify optimal material on which the best choices lie [9].A number of knowledge-based and intellectual database systems has also been developed for materials selection in mechanical design. These methods are apt for probing and not for choosing material based on values.

For selecting material based on values, an approach called Weighted Property Method (WPM) is developed, when several properties are taken into consideration. This numerical method grades the candidate materials on the basis of their performance indices, calculated from simple mathematics.

In this analysis, a numerical methodology based on WPM is explained to select material which entail mechanical properties like corrosion, wear resistance, hardness, ultimate yield strength, tensile etc. This method, uses a new digital 
logic (DL) together with a non-linear approach for scaling the properties. This method helps in quantitative analysis of selected material. Thus the decision maker can adopt this method to accomplish the best material among the selected materials.

\section{NUMERICAL METHODOLOGIES}

Digital Logic Method and Modified Digital Logic method (MDL) which is the combination of non-linear normalization with digital logic method is employed to solve problems involving selection of the material among a finite number of alternatives. These alternatives and attributes used for material selection varies from one task to other task. The various steps used in these two methods are as follows.

\subsection{Steps used in Digital Logic Method}

\section{Step1: Obtaining the Weighting Factor $(\alpha)$}

The weighting factor is obtained from the positive decision table in which each of the attributes are compared with one another and from which the relative emphasis coefficient or weighting factor is determined. In the table the attributes to be compared are tabulated on the left side and the number of possible decision are calculated on the other side. The attribute with higher importance is given a value one (1) and the attribute with lower importance is given a value zero $(0)$. The number of possible decision depends upon the number of attributes. The number of possible decision is calculated by using the formula $\mathrm{N}=\mathrm{n}(\mathrm{n}-1) / 2$. The ratio of positive decision to the number of possible decision gives the weighting factor.

Table -1: Evaluation of weighting factor

\begin{tabular}{|c|c|c|c|c|c|c|c|c|}
\hline \multirow[t]{2}{*}{ properties } & \multicolumn{6}{|c|}{$\begin{array}{l}\text { No. of possible } \\
\text { decision } \\
{[\mathrm{N}=\mathrm{n}(\mathrm{n}-1) / 2]}\end{array}$} & \multirow[t]{2}{*}{$\begin{array}{l}\text { Positive } \\
\text { decision }\end{array}$} & \multirow{2}{*}{$\begin{array}{l}\text { Weigh } \\
\text { ing } \\
\text { factor( } \\
\alpha)\end{array}$} \\
\hline & 1 & 2 & 3 & 4 & 5 & 6 & & \\
\hline $\mathrm{A}$ & 1 & 1 & 1 & & & & 3 & 0.5 \\
\hline $\mathrm{B}$ & 0 & & & 1 & 1 & & 2 & 0.33 \\
\hline $\mathrm{C}$ & & 0 & & 0 & & 1 & 1 & 0.166 \\
\hline $\mathrm{D}$ & & & 0 & & 0 & 0 & 0 & 0 \\
\hline
\end{tabular}

\section{Step 2: Evaluation of Scaled Property Value:}

The scaled property value is calculated for beneficial (where higher value is required) and non-beneficial (where lower value is required) attributes. The scaled property value (Y) is calculated in order to obtain the performance indices on which the rank is based.

The scaled property value for beneficial attributes is calculated by using the formula

$$
\mathrm{Y}=\frac{\text { numerical value of the property }}{\text { maximum value in the list }} \times 100
$$

The scaled property value for non-beneficial attributes is calculated by using the relation

$$
\mathrm{Y}=\frac{\text { minimum value in the list }}{\text { numerical value of the property }} \times 100
$$

\section{Step 3: Determination of Performance Indices $(\gamma)$}

The performance indices for each alternative is equal to the summation of scaled property values of the alternative and the weighting factor calculated for each of their attributes. The performance indices is given by $\gamma=\sum_{i=1}^{n} Y_{i} \propto_{i}$, ' $\mathrm{i}$ ' is summed over all $\mathrm{n}$ relevant properties.

\section{Step 4: Ranking of Materials:}

The performance indices determines the order of ranking of the materials, materials with higher performance indices is given rank one and second most value is given rank two and so on.

\subsection{Steps used in Modified Digital Logic method}

Ranking of materials involves mainly four steps. (a) Procurement of weighting factor from positive decision table, (b) obtaining the constant values for scaled property value, (c) evaluation of scaled property value, (d) Calculation of performance indices, and finally ranking the materials with respect to performance indices.

\section{Step 1: Procurement of Weighting Factor}

\section{Step 1.1 Preparation of Positive Decision Table}

As the factors are considered, they are of two types, beneficial (i.e. higher values are desired) and non-beneficial (i.e. lower values are desired). Positive decision table is prepared in order to get the weighting factor values. To determine the relative importance between two goals or properties, a goal table is constructed in which the goals or properties are tabulated on left side and the relative importance between the properties is done on right side of the table. While considering two properties for a material, each property is given a value based on their importance. Property with more important is assigned a value of 3, property with least important is assigned a value of 1 , and two properties with equal importance is assigned equal numerical values of two 2 as represented in the table 1 . The number of possible decision in the right hand side of the table depends upon the number of properties. It is calculated using the formula $[\mathrm{N}=\mathrm{n}(\mathrm{n}-1)]$, where $\mathrm{n}$ denotes the number of properties.

\section{Step 1.2 Evaluation of Weighting Factor:}

In order to evaluate weighting factor, the values for relative importance of that property are summed up to acquire positive decision. The weighting factor $(\alpha)$ is obtained by dividing the positive decision for each goal by N' i.e. [2n (n$1)], \mathrm{n}$ denotes the number of properties. 
Table2: Evaluation of Weighting Factor

\begin{tabular}{|l|l|l|l|l|l|l|l|l|}
\hline \multirow{2}{*}{ properties } & \multicolumn{9}{|l|}{$\begin{array}{l}\text { No. of possible } \\
\text { decision } \\
{[\mathrm{N}=\mathrm{n}(\mathrm{n}-1) / 2]}\end{array}$} & $\begin{array}{l}\text { Weight } \\
\text { Positive } \\
\text { decision }\end{array}$ \\
\cline { 2 - 8 } & 1 & 2 & 3 & 4 & 5 & 6 & & $\begin{array}{l}\text { ing } \\
\text { factor( } \\
\alpha)\end{array}$ \\
\hline A & 2 & 3 & 1 & & & & 6 & 0.1 \\
\hline B & 2 & & & 2 & 3 & & 7 & 0.116 \\
\hline C & & 1 & & 2 & & 2 & 5 & 0.083 \\
\hline D & & & 3 & & 1 & 2 & 6 & 0.1 \\
\hline$\alpha=$ positive decision / [2n(n-1)] (1) \\
\hline
\end{tabular}

\section{Step 2: Scaled Property Value(Y)}

\section{Step 2.1: Evaluation of Scaled Property Value}

Any selection method in which each property is given a weightage, the ranking is based on the performance indices calculated from scaled property value. As mentioned earlier, The factors are of two types, beneficial (i.e. higher values are desired) and non-beneficial (i.e. lower values are desired) for this, two types two non-linear functions are used to evaluate scaled property value.

For beneficial factors such as tensile strength, hardness, yield strength etc. the scaled value is calculated by using the non-linear function.

$$
Y=a_{1} \ln \left(b_{1} X+c_{1}\right)
$$

$a_{1}, b_{1}$, and $c_{1}$ Are constants, $\mathrm{X}$ is the numerical value of the property.

For non-beneficial factors like cost, corrosion resistance, wear rate, etc. the scaled value is calculated by using the non-linear function:

$Y=a_{2} \ln \left\{\frac{b_{2}}{X}+c_{2}\right\}(3) a_{2}, b_{2}$ and $c_{2}$ Are constants, $\mathrm{X}$ is the numerical value of the property.

\section{Step 2.2: Obtaining the Constants}

The constant are obtained by applying the boundary condition drawn from the inference between the scaled property value and the numerical value of the property.

In order to obtain all the constants, a parameter called critical value $\left(x_{c}\right)$ is introduced in which the designer can assign a value based on the performance needed. While solving the three boundary condition, the constants for beneficial factors is obtained as:

$$
\begin{gathered}
a_{1}=-100 / \ln \left\{\frac{X_{c}}{b_{\max }-X_{c}}\right\} \\
b_{1}=\left(X_{\max }-2 X_{c}\right) / X_{c}\left(X_{\max }-X_{c}\right) \\
c_{1}=X_{\max } /\left(X_{\max }-X_{c}\right)
\end{gathered}
$$

If the numerical value of the property $(\mathrm{X})=X_{\max } / 2$, then the scaled property (Y) can be calculated directly without constants by using the non-linear function
$Y=\frac{200 X}{X_{\max }}-100(7)$ The constants for non-beneficial factors obtained by applying boundary conditions are

$$
\begin{gathered}
a_{2}=-100 / \ln \left\{\frac{-X_{\min }}{x_{\min }-X_{c}}\right\} \\
b_{2}=\left(-X_{c}^{2}+2 X_{\text {min }} X_{c}\right) /\left(X_{\text {min }}-X_{c}\right) \\
c_{2}=-X_{\text {min }} /\left(X_{\text {min }}-X_{c}\right)
\end{gathered}
$$

Like the beneficial factors, if the numerical value of the property $(X)=2\left(X_{\min }\right)$, then the scaled value is calculated using the non-linear function

$Y=\frac{200 X_{\min }}{X}-100(11)$ Thus the above equations enables the decision maker to calculate scaled property value to choose the appropriate material.

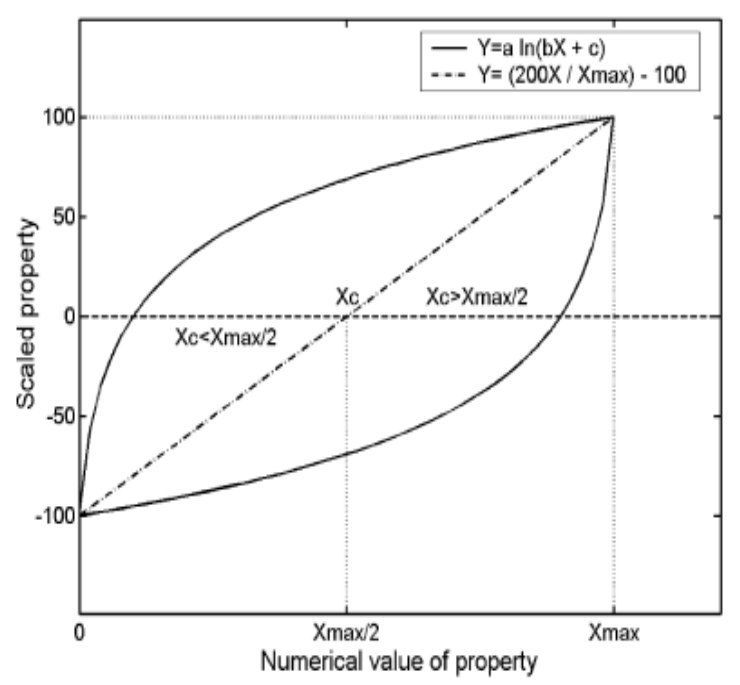

Fig -1: graph between scaled property and numerical value

\section{Step 3: Ranking of Materials:}

\section{Step 3.1: Evaluation of Performance Indices}

The material performance index $(\gamma)$ helps in ranking the material based on their values. The performance index is intended by summing up the values of weighting factor and the scaled property values for all relevant properties. Thus the formula for calculating performance indices is

$$
\gamma=\sum_{i=1}^{n} Y_{i}, \alpha_{i}
$$

\section{Step 3.2: Ranking}

The ranking of the materials having relevant factors is based on the performance indices calculated from the scaled property values and the weighting factors. The material having highest value of performance indices $(\gamma)$ is ranked as 1 , the material having second highest value is ranked as 2 and so on. 


\section{APPLYING DL AND MDL METHOD IN} CHOOSING A METAL

The selection of optimal material for a sugar industry which requires good corrosion resistance includes factors such as cost, corrosion resistance, wear rate, ultimate yield strength, hardness, tensile strength, \% elongation. All the factors are quantitative in nature and the values associated with the attributes are in different units. The beneficial factors are ultimate yield strength (YS), hardness $(\mathrm{H})$, tensile strength (TS) and \% elongation $(\% \mathrm{E})$, whereas the non-beneficial factors are cost, corrosion resistance and wear rate. In this material selection the non-beneficial factors are given higher priority order. The values of beneficial and non-beneficial for various optimal materials are given in table 3 :

Table3: optimal material and their attributes

\begin{tabular}{|l|l|l|l|l|l|l|l|}
\hline Material & YS & TS & \% E & H & Cost & CR & WR \\
\hline M1 & 382 & 728 & 48 & 98 & 112 & 0.16 & 2.75 \\
\hline M2 & 420 & 790 & 58 & 97 & 210 & 0.31 & 2.63 \\
\hline M3 & 415 & 795 & 55 & 96 & 120 & 0.05 & 2.5 \\
\hline M4 & 270 & 455 & 32 & 78 & 184 & 0.4 & 4 \\
\hline M5 & 256 & 610 & 60 & 86 & 89 & 0.01 & 2.59 \\
\hline
\end{tabular}

\subsection{Weighting Factors for Selected Attributes:}

By using the positive decision table mentioned in the methodologies, the weighting factors for attributes using Digital logic Method is calculated as

$\alpha_{Y S}=0.0952 ; \alpha_{T S}=0.0476 ; \alpha_{\% E}=0.000 ; \alpha_{H}=0.1429 ;$

$\alpha_{\text {cost }}=0.2857 ; \alpha_{\text {wear }}=0.1905$

Similarly, the weighting factors for the various attributes by MDL method are calculated as follows:

$\alpha_{Y S}=0.1190 ; \alpha_{T S}=0.1190 ; \alpha_{\% E}=0.0714 ; \alpha_{H}=0.1310 ;$

$\alpha_{\text {cost }}=0.2024 ; \alpha_{\text {wear }}=0.1667$

Step 2: scaled property values for the optimal materials by MDL method:

In order to evaluate the scaled property values for the optimal materials, the constants required for the equation (2) is obtained by considering critical values for all the attributes.

\subsection{Obtaining Constant Values}

Considering the critical values and applying it in the equation (8), (9) and (10), the constants for the nonbeneficial factors are calculated and values are shown in table 4. These constant values depend upon the critical values specified by the decision maker. Considering critical values for beneficial factors, and applying it in the equation (4), (5), and (6), the constants for various attributes are tabulated in table 5:
Table 4: constants for non-beneficial factors

\begin{tabular}{|c|l|l|l|}
\hline Values & cost & $\begin{array}{l}\text { Corrosion } \\
\text { resistance }\end{array}$ & Wear rate \\
\hline$a_{2}$ & -200.132 & 144.26 & -32.93 \\
\hline$b_{2}$ & -92.68 & 0.0150 & -51.96 \\
\hline$c_{2}$ & 1.6481 & 0.5000 & 0.8333 \\
\hline
\end{tabular}

Table 5: constants for beneficial factors

\begin{tabular}{|c|l|l|l|l|}
\hline Values & UTS & YS & $\% \mathrm{E}$ & $\mathrm{H}$ \\
\hline$a_{1}$ & -57.89 & -62.1335 & -62.1335 & -38.9871 \\
\hline$b_{1}$ & -0.0069 & 0.0114 & -0.0800 & -0.1319 \\
\hline$c_{1}$ & 5.6250 & 5.000 & 5.000 & 13.000 \\
\hline
\end{tabular}

\subsection{Evaluating Scaled Property values using}

\section{Constants}

The scaled value for each material and their attribute is calculated by using the constants and applying it in the nonlinear function (2), the $\mathrm{Y}$ value for each material is given in table 6:

Table 6: scaled property values for attributes

\begin{tabular}{|l|l|l|l|l|l|l|l|}
\hline M & Cost & CR & WR & H & YS & UTS & \%E \\
\hline M1 & 79.4 & 6.2 & 90.9 & 100 & 90.9 & 91.5 & 80 \\
\hline M2 & 42.3 & 3.22 & 95.0 & 98.9 & 100 & 99.3 & 96.6 \\
\hline M3 & 74.1 & 20 & 100 & 97.9 & 98.8 & 100 & 91.6 \\
\hline M4 & 48.3 & 2.5 & 62.5 & 79.5 & 64.2 & 57.2 & 53.3 \\
\hline M5 & 100 & 100 & 96.5 & 87.7 & 60.9 & 76.7 & 100 \\
\hline
\end{tabular}

\subsection{Scaled Property Values by using DL Method:}

The scaled property values are determined in DL method using the formulas mentioned in the procedure. The scaled property value evaluated by DL method are tabulated in table 7:

Table 7: Scaled Property Value Using Dl Method

\begin{tabular}{|c|c|c|c|c|c|c|c|}
\hline $\begin{array}{l}\text { Mate } \\
\text { rial }\end{array}$ & Cost & CR & WR & UTS & YS & $\% \mathrm{E}$ & $\mathrm{H}$ \\
\hline M1 & $\begin{array}{l}- \\
3.89\end{array}$ & $\begin{array}{l}- \\
75.2\end{array}$ & 28.08 & 52.0 & 28.2 & 13.0 & 100 \\
\hline M2 & $\begin{array}{l}- \\
64.6 \\
\end{array}$ & $\begin{array}{l}- \\
86.6 \\
\end{array}$ & 51.39 & 95.3 & 100 & 78.4 & 55 \\
\hline M3 & $-\overline{16.5}$ & $\begin{array}{l}- \\
32.1\end{array}$ & 100 & 100 & 84.3 & 53.5 & 35 \\
\hline M4 & $\begin{array}{l}- \\
57.5\end{array}$ & $\begin{array}{l}- \\
89.5\end{array}$ & -43.6 & $\begin{array}{l}- \\
36.1\end{array}$ & $\begin{array}{l}- \\
40.3\end{array}$ & $\begin{array}{l}- \\
41.5 \\
\end{array}$ & -42 \\
\hline M5 & 100 & 100 & 62.3 & 3.13 & $\begin{array}{l}- \\
45.3\end{array}$ & 100 & -24 \\
\hline
\end{tabular}

\subsection{Computation of Performance Indices $(\gamma)$}

The performance indices for each material calculated from the weighting factors and the scaled value helps in providing the ranks and in selecting the best material. The performance indices for the five optimal material in sugar 
industry by both the MDL and DL method are given in table 8:

Table 8: performance index for optimal materials

\begin{tabular}{|l|l|l|}
\hline Material & $\begin{array}{l}\text { Performance indices } \\
(\gamma) \text { by MDL method }\end{array}$ & $\begin{array}{l}\text { Performance indices } \\
(\gamma) \text { by DL method }\end{array}$ \\
\hline M1 & 12.26 & 68.82 \\
\hline M2 & 14.25 & 59.38 \\
\hline M3 & 37.05 & 73.17 \\
\hline M4 & -54.6 & 46.54 \\
\hline M5 & 49.8 & 92.76 \\
\hline
\end{tabular}

\subsection{Ranking}

By ranking the materials based on the values of performance index the materials are ranked in table 9:

Table 9: ranking of materials

\begin{tabular}{|l|l|l|}
\hline \multirow{2}{*}{ Material } & Rank & Rank \\
\cline { 2 - 3 } & MDL & DL \\
\hline M1 & 4 & 3 \\
\hline M2 & 3 & 4 \\
\hline M3 & 2 & 2 \\
\hline M4 & 5 & 5 \\
\hline M5 & 1 & 1 \\
\hline
\end{tabular}

\section{RESULTS AND DISCUSSION}

The five optimal materials are ranked according to the performance index $(\gamma)$ value by both the DL and MDL methods. The obtained results are tabulated in Table $8 \& 9$. It shows that M5 is the best material. The DL methodology provides the ranking order $\mathrm{M} 5=92.76>\mathrm{M} 3=73.17>\mathrm{M} 1=$ $68.82>\mathrm{M} 2=59.38>\mathrm{M} 4=46.54$. To validate the results of the DL methodology and to show the impact of the MDL is applied to the same numerical example and results obtained are tabulated in the Table 8. The MDL methodology provides the ranking order $\mathrm{M} 5=49.8>\mathrm{M} 3=37.05>\mathrm{M} 2=$ $14.25>\mathrm{M} 1=12.26>\mathrm{M} 4=-54.6$. The above method shows that the material 5 as the best preferred material for the application of sugar industry. The performance indices derived by using WPM method, also gives the same ranking order. All the importance of attributes give the same ranking order which is the most advantage of this material selection process for the application of sugar industry.

\section{CONCLUSIONS}

The combination of non-linear normalization with a digital method is employed. In this paper it is investigated in the material selection of sugar industry and a suitable material is selected. Certain beneficial and non-beneficial factors are considered which is taken as the main requirement. Simple mathematical calculations are used to obtain all the necessary values required. The critical value determined by the decision maker in this method plays a vital role as it allows the decision maker to enhance the human role in this process. The possibility of getting a negative value shows that the particular material can be expelled from the selection process. By Modified Digital Logic (MDL) method, we proved that material M5 is an optimum material for the sugar industry application.

\section{REFERENCES}

[1] Ashby MF, Johnson K. Materials and design: the art and science of material selection in product design. Butterworth-Heinemann; 2002.

[2] Crilly N, Moultrie J, Clarkson PJ. Seeing things: consumer response to the visual domain in product design. Des Stud 2004; 25:547-77.

[3] Dehghan-Manshadi .B, Mahmudi .H, Abedian .A, Mahmudi .R, a novel method for materials selection in mechanical design: Combination of non-linear normalization and a modified digital logic method. Materials and Design 28 (2007) 8-15.

[4] Farag MM. Quantitative methods of materials selection. In: Kutz M, editor. Handbook of materials selection; 2002.

[5] Farag MM. Quantitative methods of materials substitution: application to automotive components. Mater Des 2008; 29:374-80.

[6] Fayazbakhsh K, Abedian A, Manshadi BD, Khabbaz RS. Introducing a novel method for materials selection in mechanical design using Ztransformation in statistics for normalization of material properties. Mater Des 2009; 30: 4396-404.

[7] Jahan .A, Ismail M.Y, Sapuan S.M, Mustapha F. Material screening and choosing methods - A review. Materials and Design 31 (2010) 696-705.

[8] Maleque M.A. and Dyuti S. Materials selection of a bicycle frame using cost per unit property and digital logic methods.(IJMME), Vol. 5 (2010), No. 1, 95 100.

[9] Maleque M.A. (Member, IAENG 1, S.Dyuti ${ }^{2}$ and M.M. Rahman (Member, IAENG) ${ }^{3}$. Material Selection Method in Design of Automotive Brake Disc.

[10] Rao R.V. B.K. Patel. A subjective and objective integrated multiple attribute decision making method for material selection. Materials and Design 31 (2010) 4738-4747.

\section{BIOGRAPHIES}

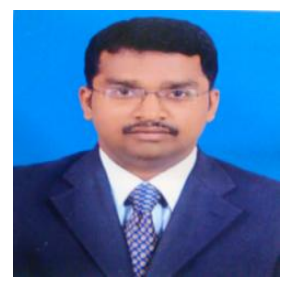

L.Anojkumar* is an Assistant Professor, Mechatronics Engineering, K S Rangasamy College of Technology, Tiruchengode, India. He completed BE (Mechanical) from K.S.Rangasamy College of Technology, Tiruchengode in the year 2005. He completed ME (Engineering Design) from Government College of Technology, Coimbatore in the year 2007. He has published five paper in international journals. He has published seven papers in national conferences and 
international conferences. He has organized two national level seminars. He is a life member of ISTE. His research interest is material selection using MCDM methods

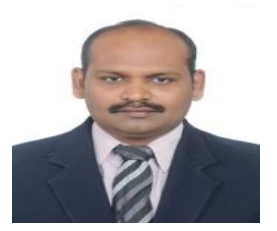

M. Ilangkumaran* is a Professor of the Mechatronics Engineering, K.S. Rangasamy College of Technology, Tiruchengode, India. He completed his BE (Mechanical) from K.S. Rangasamy College of Technology, Tiruchengode in the year 1999. He completed his ME in Industrial Engineering from Kumaraguru College of Technology, Coimbatore in the year 2001. He received his $\mathrm{PhD}$ in the area of maintenance management in the year 2010. He has published twenty six papers in international journal. He has published more than Eighteen papers in national and international conferences $\mathrm{He}$ has organized two national level seminars. He is a life member of ISTE. His research interest is maintenance management.

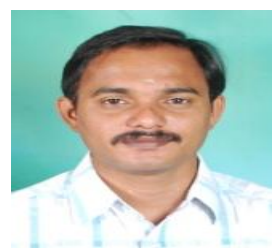

B.Kirubakaran is an Assistant Professor of Mechatronics Engineering department in K S Rangasamy College of Technology. He holds a BE in Mechanical engineering from Periyar university and $\mathrm{ME}$ in $\mathrm{CAD} / \mathrm{CAM}$ from Anna university. He is a life member of ISTE. His research interest is Maintenance Management.

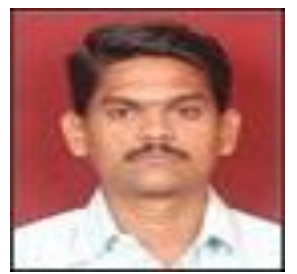

L.Arulmurugan is an Assistant Professor of Mechatronics Engineering department in $\mathrm{K} S$ Rangasamy College of Technology. $\mathrm{He}$ holds a $\mathrm{BE}$ in Electronics and Communication Engineering from Bharathiar University and ME in Applied Electronics from Anna university, Chennai. He is a life member of ISTE. His research interest is Decision Support System.

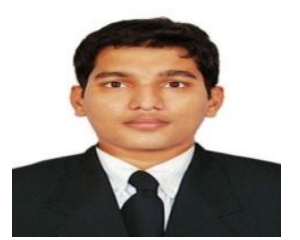

UG student studying in theDepartment of Mechatronics Engineering, K. S. Rangasamy College of Technology, Tiruchengode.

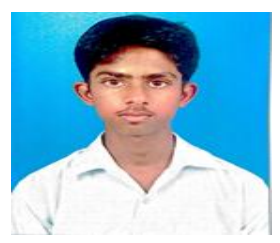

UG student studying in theDepartment of Mechatronics Engineering, K. S. Rangasamy College of Technology, Tiruchengode. 